\title{
圈/ QUEEN'S UNIVERSITY BELFAST

\section{Clear lens extraction for the management of primary angle closure glaucoma: surgical technique and refractive outcomes in the EAGLE cohort}

Day, A., Cooper, D., Burr, J. M., Foster, P., Friedman, D., Gazzard, G., Che-Hamzah, J., Aung, T., Ramsay, C. R., \& Azuara-Blanco, A. (2018). Clear lens extraction for the management of primary angle closure glaucoma: surgical technique and refractive outcomes in the EAGLE cohort. British Journal of Ophthalmology, 1658-1662. https://doi.org/10.1136/bjophthalmol-2017-311447

\section{Published in:}

British Journal of Ophthalmology

\section{Document Version:}

Peer reviewed version

Queen's University Belfast - Research Portal:

Link to publication record in Queen's University Belfast Research Portal

\section{Publisher rights}

(C) 2017 by the BMJ Publishing Group Ltd. All rights reserved.

This work is made available online in accordance with the publisher's policies. Please refer to any applicable terms of use of the publisher.

\section{General rights}

Copyright for the publications made accessible via the Queen's University Belfast Research Portal is retained by the author(s) and / or other copyright owners and it is a condition of accessing these publications that users recognise and abide by the legal requirements associated with these rights.

Take down policy

The Research Portal is Queen's institutional repository that provides access to Queen's research output. Every effort has been made to ensure that content in the Research Portal does not infringe any person's rights, or applicable UK laws. If you discover content in the

Research Portal that you believe breaches copyright or violates any law, please contact openaccess@qub.ac.uk. 
Clear lens extraction for the management of primary angle closure glaucoma:

surgical technique and refractive outcomes in the EAGLE cohort

\author{
Alexander C Day ${ }^{1}$ \\ David Cooper ${ }^{2}$ \\ Jen Burr ${ }^{3}$ \\ Paul J Foster ${ }^{1}$ \\ David S. Friedman ${ }^{4}$ \\ Gus Gazzard ${ }^{1}$ \\ Jemaima Che-Hamzah ${ }^{5}$ \\ Tin Aung ${ }^{6}$ \\ Craig Ramsay ${ }^{2}$ \\ Augusto Azuara-Blanco ${ }^{7}$
}

${ }^{1}$ NIHR Biomedical Research Centre, Moorfields Eye Hospital and University College London,

UK

${ }^{2}$ Health Services Research Unit, University of Aberdeen, Aberdeen, UK

${ }^{3}$ School of Medicine, University of St Andrews, St Andrews, UK

${ }^{4}$ John Hopkins Wilmer Eye Institute, Baltimore, USA

${ }^{5}$ Universiti Kebangsaan Malaysia Medical Centre, Kuala Lumpur, Malaysia

${ }^{6}$ Singapore Eye Research Institute, Singapore

${ }^{7}$ Centre for Public Health, Queen's University Belfast, Belfast, UK

\title{
Corresponding author:
}

Augusto Azuara-Blanco, PhD, FRCS(Ed), FRCOphth

Centre for Public Health, Queen's University Belfast

Institute of Clinical Sciences - Block A. Grosvenor Road, Belfast, BT12 6BA, UK

Telephone: 02890635887

E-mail: a.azuara-blanco@qub.ac.uk

Word count: 1737 


\section{Abstract}

Background/Aims:

To describe the surgical technique and refractive outcomes following clear lens extraction (CLE) in the EAGLE trial.

\section{Methods:}

Review of prospectively collected data from a multicentre, randomised controlled trial. comparing CLE and laser peripheral iridotomy. Eligible participants were $\geq 50$ years old, and newly diagnosed with (1) primary angle-closure (PAC) with intraocular pressure (IOP) above $30 \mathrm{mmHg}$, or (2) primary angle-closure glaucoma (PACG). We report the postoperative corrected distance visual acuity (CDVA), and refractive outcomes at 12 and 36 months postoperatively for those who underwent CLE.

\section{Results:}

Of the 419 participants, 208 were randomised to CLE. Two patients $(2 / 208,1.0 \%, 95 \% \mathrm{Cl}: 0.04$ to $3.67 \%$ ) had posterior capsule rupture requiring anterior vitrectomy and sulcus IOL placement. Mean baseline CDVA was 77.9 (SD 12.4) ETDRS letters and did not change significantly at 36 months, 79.9 (SD 10.9) letters. Mean preoperative spherical equivalent was +1.7 (SD 2.3) and +0.08 (SD 0.95) diopters (D) at 36 months. Fifty-nine percent and $85 \%$ eyes were within $\pm 0.5 \mathrm{D}$ and $\pm 1.0 \mathrm{D}$ of predicted refraction respectively at 36 months.

\section{Conclusions:}

Mean CDVA in patients undergoing clear lens extraction for angle-closure glaucoma appeared stable over the 3 year study period. Refractive error was significantly reduced with surgery but refractive predictability was sub-optimal. 


\section{Introduction}

Refractive outcomes in patients with primary angle closure glaucoma (PACG) undergoing lens extraction can be unpredictable because of the anatomical features including shallow anterior chamber depth, thickened and anteriorly positioned lens, and short axial length. Large deviations from the target refraction have been reported.[1-3] The EAGLE (Effectiveness, in Angle-closure Glaucoma, of Lens Extraction) study recently reported that PACG and PAC patients with high intraocular pressure (IOP) who were treated with clear lens extraction (CLE) had better quality of life and IOP control and required fewer medications and surgeries to control their glaucoma than those undergoing laser peripheral iridotomy (PI).[4] Visual acuity outcomes were similar between the CLE and laser PI.

Given these positive results, the decision on whether or not to perform CLE in these patients as primary therapy depends largely on an individualised approach to the risks and benefits. The EAGLE trial reported low rates of surgical complications and irreversible vision loss in both groups. In this report, we describe the surgical details, visual outcomes and postoperative refractive error of participants undergoing CLE.

\section{Materials and Methods}

The EAGLE trial recruited 419 participants with either PAC with IOP of $30 \mathrm{mmHg}$ or higher or non-severe PACG between January 2009 and December 2011.[4] Full details of the treatments are specified in the published protocol.[5] Briefly, eligible patients underwent either laser peripheral iridotomy, or CLE by phacoemulsification with a monofocal intraocular lens (IOL) implantation within 60 days of randomisation. A total of 208 patients were randomised to lens extraction. Synechiolysis was allowed according to local practice. 
Participating surgeons recorded operative details and intraoperative and post-operative complications at the time of surgery and at 6, 12, 24 and 36 months after randomisation using standardized forms. Data were collected on the predicted refraction and IOL formula used. Laser biometry was used to estimate axial length and IOL power. The IOL formula and incision axis were selected by the local surgeon. Anti-glaucomatous treatment was allowed before surgery and selected according to local practice. The most commonly used drug was prostaglandin $(n=67,54.0 \%)$ followed by beta-blocker $(n=46(37.1 \%))$ and pilocarpine $(n=41$, $33.1 \%)$.

All patients underwent subjective refraction by a masked optometrist at 12 months and 36 months postoperative. Corrected distance visual acuity was measured with Early Treatment Diabetic Retinopathy Study (ETDRS) charts under standardized illumination.[6] Mean biometry prediction errors were calculated by subtracting the postoperative spherical equivalent (SE) from the predicted spherical equivalent, allowing calculation of the mean prediction error (MPE, i.e., predicted SE minus postoperative SE).[7,8] A negative MPE indicates undercorrection (hyperopic outcome). $[7,8]$ The mean absolute error (MAE) is the mean of the individual prediction errors without regard for sign. Visual acuity and refractive results are presented where possible in accordance with the standardized reporting guidelines for cataract and refractive surgery.[9,10] We used regression analysis to explore the possible influence of the following baseline variables on refractive error: axial length, anterior chamber depth, refraction, age, visual acuity, bilateral (one or both eyes fulfilling the inclusion criteria), gender, diagnosis (PAC or PACG), and ethnicity (Chinese versus nonchinese)" 


\section{Results:}

Most surgeries $(181,87 \%)$ were performed by senior consultant glaucoma specialists. Ninetysix percent cases were performed via a clear corneal incision, and $9 \%$ required a corneal suture to facilitate wound closure (see Table 1 for participant demographic and operative details). A monofocal IOL was used in all cases. The SRK/T formula was used for IOL power calculation in over $80 \%$ cases (Table 1 ).

Table 1. Demographic and operative details

\begin{tabular}{|c|c|}
\hline & Lens extraction $(n=208)$ \\
\hline Age, years & $67.1,(8.4)$ \\
\hline Gender, M:F & $86: 122$ \\
\hline Ethnicity (Chinese) & $62(29.8 \%)$ \\
\hline $\begin{array}{l}\mathrm{N} \text { withdrawn intervention post } \\
\text { randomisation but prior to surgery? }\end{array}$ & $1(0.5 \%)$ \\
\hline Mean axial length, $\mathrm{mm}(\mathrm{SD})$ & $22.5(0.9)$ \\
\hline $\begin{array}{l}\text { Mean preoperative anterior } \\
\text { chamber depth, } \mathrm{mm}(\mathrm{SD})\end{array}$ & $2.5(0.3)$ \\
\hline $\begin{array}{l}\text { Mean preoperative spherical } \\
\text { equivalent, } D(S D)\end{array}$ & $1.7(2.3)$ \\
\hline Anaesthetic technique & $\begin{array}{c}65(31.2 \%) \text { topical and intracameral } \\
116(55.8 \%) \text { sub-Tenon's } \\
10(4.8 \%) \text { peribulbar } \\
8(3.8 \%) \text { retrobulbar } \\
9(4.3 \%) \text { general }\end{array}$ \\
\hline Incision type (if reported) & $\begin{array}{c}200(96.2 \%) \text { corneal } \\
1(0.5 \%) \text { scleral }\end{array}$ \\
\hline Incision axis at 12 o'clock & $\begin{array}{l}55(26.4 \%) 12 \text { o'clock } \\
145(69.7 \%) \text { other axis }\end{array}$ \\
\hline Wound suture & $18(8.7 \%)$ \\
\hline Intra-operative antibiotic & $\begin{array}{c}142(68.3 \%) \text { intracameral } \\
40 \text { (19.2\%) subconjunctival }\end{array}$ \\
\hline
\end{tabular}




\begin{tabular}{|l|c|}
\hline Visco-synechiolysis performed & $18(8.7 \%)$ \\
\hline Grade of surgeon lens & $181(87.0 \%)$ Consultant \\
& $16(7.7 \%)$ Associate Specialist \\
& $2(1.0 \%)$ Fellow \\
\hline IOL power used; diopters (SD) & $4(1.9 \%)$ Other \\
\hline Aimed refraction; diopters (SD) & $23.8,(2.7)$ \\
\hline IOL formula used, total number & $-0.1,(0.6)$ \\
\hline SRK-T & 164 \\
Hoffer-Q & $136(82.4 \%)$ \\
Haigis & $16(9.1 \%)$ \\
Holladay & $8(4.8 \%)$ \\
\hline Surgery time, minutes (SD) & $4(2.4 \%)$ \\
\hline
\end{tabular}

Average baseline CDVA was 77.9 (12.4) ETDRS letters and did not differ significantly at 12 months or 36 months (see table 2 ). Almost $6 \%$ eyes lost 10 or more ETDRS letters of CDVA (equivalent to 2 line logMAR) at 12 months and $10 \%$ eyes lost 10 or more ETDRS letters at 36 months (see Figure 1). Two patients $(2 / 208,1.0 \%, 95 \% \mathrm{Cl}: 0.04$ to $3.67 \%)$ had posterior capsule rupture requiring anterior vitrectomy and sulcus IOL placement, but these 2 eyes had satisfactory visual outcomes with no visual acuity loss of 10 or more ETDRS letters.

Postoperative target refraction and postoperative manifest refraction data was available for 154 eyes $(154 / 208,74 \%)$; of which, the IOL power formula used was available for 127 eyes (61\%). The mean postoperative target refraction was -0.1D spherical equivalent (SD 0.6D). The overall mean prediction error (MPE) at 36 months was +0.16D (SD: 0.84). The mean absolute prediction error (MAE) at 36 months was +0.59D (SD =0.61D). (see Table 2). Overall fifty-nine percent and $85 \%$ of eyes were within $\pm 0.5 \mathrm{D}$ and $\pm 1.0 \mathrm{D}$ of target refraction, respectively (see Table 3 including comparisons by IOL formula used, Figure 2). Table 4 shows the proportion eyes within $\pm 0.25, \pm 0.50$ and $\pm 1.0 \mathrm{D}$ predicted refraction by axial length 
$(<22 \mathrm{~mm}$ or $\geq 22 \mathrm{~mm})$. Eyes with axial length of $<22 \mathrm{~mm}$ were significantly more likely to have a postoperative refractive outcome $>1 \mathrm{D}$ different from that predicted. Figure 3 shows the postoperative refractive cylinder at 36 months. Regression of attempted spherical equivalent correction vs achieved spherical equivalent correction is displayed in Figure 4.

The demographic and ocular variables explored were not associated with refractive predictability $(p>0.05)$. Among participants with loss of vision one had irreversible and severe visual loss due to malignant glaucoma and uncontrolled IOP, but no specific complications were reported in other patients with decreased visual acuity. Decreased visual acuity was not considered to be permanent by the local clinician.

Table 2. Mean pre- and postoperative spherical equivalent refraction and visual acuity

\begin{tabular}{lcc}
\hline Spherical equivalent, diopters & $\mathbf{n}$ & mean (SD) \\
\hline Baseline & 189 & $+1.7(2.3)$ \\
\hline $\mathbf{1 2}$ months & 176 & $+0.01(0.97)$ \\
\hline $\mathbf{3 6}$ months & 168 & $+0.08(0.95)$ \\
\hline ETDRS visual acuity, letters & $\mathrm{n}$ & mean (SD) \\
\hline Baseline & 207 & $77 \cdot 9(12 \cdot 4)$ \\
\hline $\mathbf{1 2}$ months & 183 & $81.6(9.3)$ \\
\hline $\mathbf{3 6}$ months & 176 & $79 \cdot 9(10 \cdot 9)$ \\
\hline
\end{tabular}


Table 3: Mean prediction errors, absolute prediction errors and proportion eyes within \pm 0.25 , \pm 0.50 and \pm 1.0 diopters (D) predicted refraction.

\begin{tabular}{|c|c|c|c|c|c|c|}
\hline $\begin{array}{l}\text { IOL } \\
\text { formula }\end{array}$ & $\begin{array}{c}n \\
\text { eyes }\end{array}$ & $\begin{array}{c}\text { Mean } \\
\text { prediction } \\
\text { error at } \\
36 \mathrm{~m}, \mathrm{SD}, \\
\text { range } \mathrm{X}-\mathrm{Y}\end{array}$ & $\begin{array}{c}\text { Absolute } \\
\text { prediction } \\
\text { error at } \\
36 \mathrm{~m}, \mathrm{SD}, \\
\text { range } \mathrm{X}-\mathrm{Y}\end{array}$ & $\begin{array}{c}\% \\
\text { within } \pm 0.25 D \\
\text { target }\end{array}$ & $\begin{array}{c}\% \\
\text { within } \pm 0.50 \mathrm{D} \\
\text { target }\end{array}$ & $\begin{array}{c}\% \\
\text { within } \pm 1.0 \mathrm{D} \\
\text { target }\end{array}$ \\
\hline Hoffer Q & 12 & $\begin{array}{c}-0.37, \text { SD: } \\
1.71\end{array}$ & $\begin{array}{c}1.11, \mathrm{SD}: \\
1.32\end{array}$ & $25 \%$ & $42 \%$ & $67 \%$ \\
\hline $\mathrm{SRK} / \mathrm{T}$ & 105 & $\begin{array}{c}+0.28, \text { SD: } \\
0.76\end{array}$ & $\begin{array}{c}0.61, \text { SD: } \\
0.53\end{array}$ & $32 \%$ & $55 \%$ & $84 \%$ \\
\hline Haigis & 6 & $\begin{array}{l}+0.025 \\
\text { SD: } 0.38\end{array}$ & $\begin{array}{c}0.30, \text { SD: } \\
0.20\end{array}$ & $50 \%$ & $83 \%$ & $100 \%$ \\
\hline $\begin{array}{l}\text { All } \\
\text { overall* }\end{array}$ & 150 & $\begin{array}{c}+0.16, \text { SD: } \\
0.84\end{array}$ & $\begin{array}{c}0.59 D, \text { SD: } \\
0.61\end{array}$ & $35 \%$ & $59 \%$ & $85 \%$ \\
\hline
\end{tabular}

*Data for Holladay ( $n=4)$, and missing IOL power formula used $(n=23)$, also included.

Table 4. Proportion eyes within $\pm 0.25, \pm 0.50$ and \pm 1.0 diopters (D) predicted refraction by axial length $(<22 \mathrm{~mm}$ or $\geq 22 \mathrm{~mm})$.

\begin{tabular}{|l|c|c|c|}
\hline & $\begin{array}{c}\% \text { within } \pm 0.25 \mathrm{D} \\
\text { target }\end{array}$ & $\begin{array}{c}\% \text { within } \pm 0.50 \mathrm{D} \\
\text { target }\end{array}$ & $\begin{array}{c}\text { \% within } \pm 1.0 \mathrm{D} \\
\text { target }\end{array}$ \\
\hline $\begin{array}{l}\text { Axial length }<22 \mathrm{~mm} \\
{[\mathrm{n}=36]}\end{array}$ & $\mathbf{3 3 \%}$ & $\mathbf{5 0 \%}$ & $\mathbf{6 4 \%}$ \\
\hline $\begin{array}{l}\text { Axial length } \geq 22 \mathrm{~mm} \\
{[\mathrm{n}=112]}\end{array}$ & $\mathbf{3 5 \%}$ & $\mathbf{6 1 \%}$ & $\mathbf{9 2 \%}$ \\
\hline All $[\mathrm{n}=148]$ & $\mathbf{3 4 \%}$ & $\mathbf{5 8 \%}$ & $\mathbf{8 5 \%}$ \\
\hline
\end{tabular}




\section{Discussion:}

In the EAGLE trial, $59 \%$ and $85 \%$ of eyes undergoing CLE were within $\pm 0.5 \mathrm{D}$ and $\pm 1.0 \mathrm{D}$ of predicted refraction, respectively. Refractive outcomes in patients with PACG undergoing lens extraction are typically believed to be unpredictable due to the anatomical features including shallow anterior chamber depth, thickened and anteriorly positioned lens, and short axial length. Overall our refractive outcomes were similar to previous large datasets of patients undergoing cataract surgery with values being $49-60 \%$ and $80-87 \%$ eyes within $\pm 0.5 \mathrm{D}$ and $\pm 1.0 \mathrm{D}$ of predicted refraction respectively using data from the UK;[11] and are in keeping with the previous refractive outcome benchmarking target set by the UK Royal College of Ophthalmologists of $85 \%$ within $\pm 1.0 \mathrm{D}$ target.[12] The refractive accuracy is however less, than that reported in an analysis of 17056 eyes undergoing cataract surgery in Sweden, where $71 \%$ were within $\pm 0.5 \mathrm{D}$ and $93 \%$ within $\pm 1.0 \mathrm{D}$.[13] The EAGLE results compare favourably to previous studies of refractive outcomes in patients with PACG where $49-68 \%$ eyes (depending on the IOL power formula used) were reported to be within $\pm 0.5 \mathrm{D}$ target a study of 63 eyes[14] and 77\% eyes within 1.0D target refraction in study of 49 eyes with primary angle closure glaucoma.[15]

The mean prediction error varied by IOL formula used, being - $0.4 \mathrm{D}$ for Hoffer $Q$ and +0.3 for $\mathrm{SRK} / \mathrm{T}$, indicating undercorrection and overcorrection (myopic outcome) respectively for these IOL formulae. SRK/T was used in $83 \%$ cases and thus based on the data available, clinicians would typically experience a myopic overcorrection in patients with similar characteristics than those enrolled in EAGLE. Mean IOL formula prediction errors must be close to zero to minimize the systematic error from an incorrect IOL formula constant.[16,17] However this was not possible as keratometry data was not recorded as part of the EAGLE dataset. Simple comparison of the MAEs (with non-zero MPE values) between different 
formulas used in EAGLE would be biased, and only six eyes used Haigis formula, but the MPE of 0.03 may suggest that the lens constants used with this formula were close to optimal. Interestingly a tendency towards myopic overcorrection in eyes with angle closure was reported by Kim et al.[15]; whilst Joo et al. reported a myopic overcorrection when using the Hoffer $Q$ formula; and hyperopic undercorrection when using either SRK/T or the Haigis formulae.[18] The myopic overcorrection in eyes with PAC may be associated with a high lens vault (defined as the perpendicular distance between the anterior pole of the crystalline lens and a horizontal line connecting the two scleral spurs), and so an anteriorly positioned crystalline lens.[15] It is possible other factors may influence the refractive predictability such as the anterior chamber configuration and a large lens vault [19].

In the EAGLE trial visual acuity outcomes in the CLE group were similar to the laser PI group. There is limited data for comparison of visual outcomes as reported by reviews on refractive lens exchange.[20] A recent large dataset analysis on the results of cataract surgery in the UK reported visual acuity loss (defined as $\geq 0.30 \log$ MAR loss) was $1.5 \%$ for the overall cohort and 6.9\% for those with a preoperative visual acuity of $0.00 \operatorname{logMAR}$ or better.[21]

Posterior capsule rupture (PCR) is associated with significantly higher risk of poor visual outcomes[22] and PCR has been reported to be the only potentially modifiable adverse risk indicator for visual loss following cataract surgery $(\mathrm{OR}=5.7),[22]$ but in the EAGLE trial the frequency of visual acuity loss was not different between the CLE and the laser PI groups. Overall PCR rates from large cataract outcome datasets are approximately 1.9 2.1\%.[21,23,24]. In an analysis by Day et al. of 105078 eyes undergoing cataract surgery, PCR rates showed little change with axial length except for an increase in eyes with axial length of $<20.0 \mathrm{~mm}$ (3.6\% PCR rate vs $2.0 \%$ for those $\geq 20.0 \mathrm{~mm}$ axial length, OR 1.9).[25] In the EAGLE study two participants (2/208, $0.96 \%, 95 \% \mathrm{Cl}: 0.04$ to $3.67 \%)$ had PCR. Based on the greater 
than average complexity of surgery in eyes with PACG, the relatively low rate of PCR in EAGLE participants may reflect the experience of the operating surgeons or the fact that the relatively soft lens material could be easily removed.

EAGLE patients that underwent CLE had correction of their preoperative refractive error with emmetropia targeted in the vast majority of cases. Conversely EAGLE patients, that were randomized to laser peripheral iridotomy had a mean hyperopic error (+0.92D [SD 2.8D] at 36 months. Thus those that were randomized to CLE would have had unaided distance visual acuity improvement for both distance, intermediate and near, and refractive correction may have impacted the patient reported outcome questionnaires[26] with a change of almost $6 \%$ for EQ5D, 7\% for the Glaucoma Utility Index, and 26\% for the National Eye Institute VFQ-25 relative to those that underwent laser peripheral iridotomy.[4] The influence of refractive error on quality of life may deserve further analysis. Although refractive outcomes are important factors in determining the risk/benefit ratio of clear lens extraction as a first treatment for angle closure disease, possible long-term complications including the risk of retinal detachment after lens extraction should also be considered. The risk of pseudophakic retinal detachment is estimated to be $1.0 \%$ at 4 years.[27] This is particular important because randomised controlled trials are not useful to detect and quantify the frequency of uncommon complications.

As previously discussed, the main advantages of the EAGLE study are its prospective data collection, pragmatic design, large sample size, the involvement of centres in the UK and Asia and the masking of the clinical assessments in particular for visual acuity and refraction, which kept the potential risk of bias to a minimum. [4] There are also a number of limitations, these include that the CLE was not masked from participants and there were missing data issues 
such as seen by the proportion of patients with complete biometric and refraction data. However there is no reason to suggest that missing data could have introduced bias.

In conclusion CLE for a subset of PAC or PACG patients is a suitable option, but an individualised decision on the risks and benefits of clear lens extraction versus laser peripheral iridotomy is warranted. This should include consideration of the potential error in refractive outcomes, particularly in eyes with short axial length. 


\section{Acknowledgement}

This research grant is funded by the Medical Research Council (MRC G0701604) and managed by the National Institute for Health Research (NIHR-EME 09-800-26) on behalf of the MRC-NIHR partnership. The views and opinions expressed in this article are those of the authors and do not necessarily reflect those of the MRC, the NIHR HTA program, the NIHR, the National Health Service or the Department of Health, or the funders that provided institutional support for the study.

\section{Competing interests}

None declared

\section{Contributorship}

$A A-B$ and JB are chief investigators of the EAGLE trial. $A C D$ and $D C$ led the data analysis. AA-B and ACD led the drafting of the manuscript. All authors were actively involved in the interpretation of data and editing of the manuscript. 


\section{Legends:}

Figure 1.

Change in logMAR lines of CDVA at 36 months;

Figure 2.

Postoperative spherical equivalent refraction at 36 months.

Figure 3.

Postoperative refractive cylinder at 36 months.

Figure 4.

Comparison of spherical equivalent attempted correction (preoperative minus predicted spherical equivalent) and achieved spherical equivalent correction (preoperative minus achieved spherical equivalent refraction) at 36 months. 


\section{References:}

1 Tarongoy P, Ho CL, Walton DS. Angle-closure glaucoma: the role of the lens in the pathogenesis, prevention, and treatment. Surv Ophthalmol 2009;54:211-25. doi:10.1016/j.survophthal.2008.12.002

2 Kugelberg M, Lundström M. Factors related to the degree of success in achieving target refraction in cataract surgery: Swedish National Cataract Register study. J Cataract Refract Surg 2008;34:1935-9. doi:10.1016/j.jcrs.2008.06.036

3 Seo S, Lee CE, Kim YK, et al. Factors affecting refractive outcome after cataract surgery in primary angle-closure glaucoma. Clin Experiment Ophthalmol 2016;44:693-700. doi:10.1111/ceo.12762

4 Azuara-Blanco A, Burr J, Ramsay C, et al. Effectiveness of early lens extraction for the treatment of primary angle-closure glaucoma (EAGLE): a randomised controlled trial. Lancet Lond Eng/ 2016;388:1389-97. doi:10.1016/S0140-6736(16)30956-4

5 Azuara-Blanco A, Burr JM, Cochran C, et al. The effectiveness of early lens extraction with intraocular lens implantation for the treatment of primary angle-closure glaucoma (EAGLE): study protocol for a randomized controlled trial. Trials 2011;12:133. doi:10.1186/1745-6215-12-133

6 Ferris FL, Kassoff A, Bresnick GH, et al. New visual acuity charts for clinical research. Am J Ophthalmol 1982;94:91-6.

7 MacLaren RE, Natkunarajah M, Riaz Y, et al. Biometry and formula accuracy with intraocular lenses used for cataract surgery in extreme hyperopia. Am J Ophthalmol 2007;143:920-31. doi:10.1016/j.ajo.2007.02.043

8 Terzi E, Wang L, Kohnen T. Accuracy of modern intraocular lens power calculation formulas in refractive lens exchange for high myopia and high hyperopia. J Cataract Refract Surg 2009;35:1181-9. doi:10.1016/j.jcrs.2009.02.026

9 Waring GO, Reinstein DZ, Dupps WJ, et al. Standardized graphs and terms for refractive surgery results. J Refract Surg Thorofare NJ 1995 2011;27:7-9. doi:10.3928/1081597X20101116-01

10 Reinstein DZ, Archer TJ, Srinivasan S, et al. Standard for Reporting Refractive Outcomes of Intraocular Lens-Based Refractive Surgery. J Refract Surg 2017;33:218-22. doi:10.3928/1081597X-20170302-01

11 Gale RP, Saldana M, Johnston RL, et al. Benchmark standards for refractive outcomes after NHS cataract surgery. Eye 2007;23:149-52. doi:10.1038/sj.eye.6702954

12 The Royal College of Ophthalmologists. Cataract Surgery Guidelines. 2010.https://www.rcophth.ac.uk/wp-content/uploads/2014/12/2010-SCl-069-CataractSurgery-Guidelines-2010-SEPTEMBER-2010.pdf 
13 Behndig A, Montan $\mathrm{P}$, Stenevi $\mathrm{U}$, et al. Aiming for emmetropia after cataract surgery: Swedish National Cataract Register study. J Cataract Refract Surg 2012;38:1181-6. doi:10.1016/j.jcrs.2012.02.035

14 Joo J, Whang W-J, Oh T-H, et al. Accuracy of Intraocular Lens Power Calculation Formulas in Primary Angle Closure Glaucoma. Korean J Ophthalmol KJO 2011;25:375-9. doi:10.3341/kjo.2011.25.6.375

15 Kim YC, Sung MS, Heo H, et al. Anterior segment configuration as a predictive factor for refractive outcome after cataract surgery in patients with glaucoma. BMC Ophthalmol 2016;16. doi:10.1186/s12886-016-0359-1

16 Hoffer KJ, Aramberri J, Haigis W, et al. Protocols for Studies of Intraocular Lens Formula Accuracy. Am J Ophthalmol 2015;160:403-5.e1. doi:10.1016/j.ajo.2015.05.029

17 Aristodemou P, Knox Cartwright NE, Sparrow JM, et al. Statistical Analysis for Studies of Intraocular Lens Formula Accuracy. Am J Ophthalmol 2015;160:1085-6. doi:10.1016/j.ajo.2015.08.010

18 Joo CK, Shin JA, Kim JH. Capsular opening contraction after continuous curvilinear capsulorhexis and intraocular lens implantation. J Cataract Refract Surg 1996;22:58590.

19 Kim YC, Sung MS, Heo H, Park SW. Anterior segment configuration as a predictive factor for refractive outcome after cataract surgery in patients with glaucoma. BMC Ophthalmol. 2016 18;16:179. doi:10.1186/s12886-016-0359-1

20 Nanavaty MA, Daya SM. Refractive lens exchange versus phakic intraocular lenses. Curr Opin Ophthalmol 2012;23:54-61. doi:10.1097/ICU.0b013e32834cd5d1

21 Day AC, Donachie PHJ, Sparrow JM, et al. The Royal College of Ophthalmologists' National Ophthalmology Database study of cataract surgery: report 1, visual outcomes and complications. Eye Lond Engl 2015;29:552-60. doi:10.1038/eye.2015.3

22 Sparrow JM, Taylor H, Qureshi K, et al. The Cataract National Dataset electronic multicentre audit of 55,567 operations: risk indicators for monocular visual acuity outcomes. Eye Lond Engl 2012;26:821-6. doi:10.1038/eye.2012.51

23 Jaycock $\mathrm{P}$, Johnston RL, Taylor $\mathrm{H}$, et al. The Cataract National Dataset electronic multicentre audit of 55,567 operations: updating benchmark standards of care in the United Kingdom and internationally. Eye Lond Engl 2009;23:38-49. doi:10.1038/sj.eye.6703015

24 Lundström $M$, Behndig A, Kugelberg $M$, et al. Decreasing rate of capsule complications in cataract surgery: eight-year study of incidence, risk factors, and data validity by the Swedish National Cataract Register. J Cataract Refract Surg 2011;37:1762-7. doi:10.1016/j.jcrs.2011.05.022

25 Day AC, Donachie PHJ, Sparrow JM, et al. The Royal College of Ophthalmologists' National Ophthalmology Database Study of cataract surgery: report 2, relationships of 
axial length with ocular copathology, preoperative visual acuity, and posterior capsule rupture. Eye Lond Engl 2015;29:1528-37. doi:10.1038/eye.2015.198

26 Traverso CE. Clear-lens extraction as a treatment for primary angle closure. The Lancet 2016;388:1352-4. doi:10.1016/S0140-6736(16)31746-9

27 Daien V, Le Pape A, Heve D, et al. Incidence, Risk Factors, and Impact of Age on Retinal Detachment after Cataract Surgery in France: A National Population Study.

Ophthalmology 2015;122:2179-85. doi:10.1016/j.ophtha.2015.07.014 